\title{
USO DOS MAPAS CONCEITUAIS COMO FERRAMENTA DE AVALIAÇÃO QUALITATIVA, COM ÊNFASE NO ENSINO DE FÍSICA
}

\author{
M. P. DANTAS ${ }^{1}$, F. U. SILVA ${ }^{1}$, J. C. S. BORGES ${ }^{1, *}$ \\ ${ }^{1}$ Instituto Federal do Rio Grande do Norte \\ cousteau.borges@ifrn.edu.br*
}

Submetido 15/05/2017 - Aceito 12/06/2018

DOI: $10.15628 /$ holos.2018.5932

\section{RESUMO}

Este artigo contém uma análise do uso dos mapas conceituais na educação (com ênfase no ensino de física) e uma proposta de utilizá-lo como ferramenta de avaliação qualitativa. Através de uma pesquisa de revisão bibliográfica, foram obtidas informações que revelaram a valiosa ferramenta que são os mapas conceituais para a educação. O mapa conceitual é uma estratégica metodológica gráfica que tem por objetivo organizar, representar e criar conhecimento, através relações entre conceitos, criando proposições. Essa ferramenta é fundamentada na teoria da assimilação de Ausubel e por esse motivo possui uma estrutura hierárquica, sua elaboração e leitura exigem um menor esforço cognitivo em relação a textos escritos. Por esse motivo, os mapas conceituais são ótimas ferramentas para a avaliação qualitativa.

PALAVRAS-CHAVE: Mapa Conceitual, Avaliação Qualitativa, Teoria da Assimilação, Estrutura Hierárquica.

\section{USE OF CONCEPTUAL MAPS AS A TOOL FOR QUALITATIVE EVALUATION, WITH EMPHASIS OF PHYSICAL EDUCATION}

\begin{abstract}
These articles contain an analysis of the use of concept maps in education (with an emphasis on physical education) and a proposal to use it as a qualitative assessment tool. Through a literature review of research, information that revealed valuable tool that the conceptual maps for education were obtained. The conceptual map is a graphical methodological strategy which aims to organize, represent and create knowledge through relationships between concepts,
\end{abstract}

creating propositions. This tool is based on Ausubel's assimilation theory and therefore has a hierarchical structure, its preparation and reading require less cognitive effort in relation to written texts. For this reason, the conceptual maps are great tools for qualitative evaluation.

KEYWORDS: Concept Map, Qualitative Evaluation, Theory of Assimilation, Hierarchical Structure. 


\section{INTRODUÇÃO}

A atuação do professor impõe a esse profissional a necessidade de compreender como ocorre a aprendizagem do seu aluno, deste modo é imprescindível a discussão, na formação de professores, de referenciais teóricos que possam orientar e problematizar a prática docente (Ostermann e Cavalcante, 2010). Essas referências podem ser obtidas nas diferentes correntes da psicologia, suas teorias são genericamente nomeadas como 'teorias da aprendizagem'. Essas teorias tem o objetivo criar modelos para explicar e melhorar a qualidade do processo de aprendizagem do indivíduo.

A teoria cognitiva, por exemplo, busca compreender a estrutura e o funcionamento da mente (Recardo, 2012). Entre os seus autores se destaca David Ausubel, por suas contribuições para entendimento do processo de aprendizagem. A essência da teoria da aprendizagem dele consiste na afirmativa de que a aprendizagem só é significativa quando as novas ideias se relacionam e interagem de forma relevante com as ideias já existentes na estrutura cognitiva do aprendiz. Para ele a aprendizagem significativa se dá prioritariamente por recepção e o novo material apresentado pode apenas ser potencialmente significativo, pois sua relevância se dá em função de quem aprende (Ausubel, 2003).

Nesse sentido, o professor assume um papel fundamental na elaboração de estratégias metodológicas que conduzam a essa aprendizagem. Ferramentas como os mapas conceituais podem ser bastante úteis para essa tarefa, eles foram desenvolvidos da necessidade dos pesquisadores em acompanhar e compreender as mudanças na maneira como as crianças aprendem ciência, para isso foi criado uma ferramenta gráfica, utilizada para organizar, representar e criar conhecimento (Novak e Cañas, 2010). Os mapas conceituais foram desenvolvidos para auxiliar na obtenção da aprendizagem significativa, eles podem ser utilizados em todas as etapas necessárias para conduzir a essa aprendizagem, principalmente na avaliação onde essa ferramenta visualiza a organização conceitual que o aluno atribui a determinado conhecimento (Moreira, 1997).

Esse trabalho, tem como objetivo fazer uma análise do uso dos mapas conceituais no ensino de física e propor uma estratégia metodológica da utilização deles como ferramenta de avaliação qualitativa, que auxilie as ações do professor em sala.

Como suporte para elaboração dos mapas conceituais será indicado o programa Cmap Tools, essa ferramenta digital pode ser baixada gratuitamente pela internet e oferece diversos recursos que também serão discutidos nesse artigo.

\section{TEORIA DA APRENDIZAGEM SIGNIFICATIVA}

A teoria da assimilação de Ausubel, também conhecida como a teoria da aprendizagem significativa, é uma teoria cognitiva que procura entender como ocorrem os processos internos da mente humana, como ela assimila, organiza e retém o conhecimento (Ricardo, 2012). Ela surge como resposta ao colapso da orientação teórica neobehaviorista e da abordagem construtivista para aprendizagem (Ausubel, 2003). Como já foi mencionada, a aprendizagem significativa Ausubeliana ocorre essencialmente por recepção e geralmente através da instrução verbal expositiva e não por descoberta como alguns teóricos defendem. Em relação às criticas 
apresentadas, por outros movimentos da psicologia, a aprendizagem por recepção e ao método expositivo, Ausubel argumenta que algumas práticas expositivas tornam essa aprendizagem mecânica e passiva, não o método em si.

1.Uso prematuro de técnicas verbais puras com alunos imaturos em termos cognitivos.

2. Apresentação arbitrária de fatos não relacionados sem quaisquer princípios de organização ou de explicação.

3. Não integração de novas tarefas de aprendizagem com materiais anteriormente apresentados.

4. Utilização de procedimentos de avaliação que avaliam somente a capacidade de se reconhecerem fatos discretos, ou de se reproduzirem ideias pelas mesmas palavras ou no contexto idêntico ao encontrado originalmente. (Ausubel, 2003).

Por outro lado, segundo Tavares, 2007, a aprendizagem significativa ocorre quando novos conhecimentos se relacionam de forma não arbitraria e não literal com conhecimentos já existentes na estrutura cognitiva do aprendiz. Esse conhecimento pré-xistente, Ausubel denomina como subsunçor ou ideia ancora. Segundo ele a estrutura cognitiva se organiza hierarquicamente conforme a área do conhecimento, no qual os conceitos mais inclusivos subordinam conceitos mais específicos e menos abrangentes, sua estrutura é dinâmica e muda a partir dois processos; a diferenciação progressiva e a reconciliação integradora.

Além desses dois processos que caracterizam as mudanças na estrutura cognitiva, são observados outras três formas de aprendizagem significativa, que segundo Novak e Gowin, 1996 são: Por subordinação, quando o novo conhecimento adquire significado a partir de ideias ancora mais gerais e inclusivas na estrutura cognitiva do aprendiz; Por superordenação, quando o novo conhecimento subordina os subsurçores que lhe deram origem e por combinação, quando o conhecimento novo não subordina e não é subordinado por nenhum subsuçor, ele apenas se utiliza de significados comuns dos conhecimentos que lhe deram origem.

Vale reforça que no processo da aprendizagem significativa os novos conhecimentos adquirem significado a partir de relações relevantes feitas com os subsurçores (Moreira, 2012). Nesse processo os conhecimentos existentes se diferenciam, tornam-se mais estável na estrutura cognitiva, o que é denominado de diferenciação progressiva. Simultaneamente ocorre a reconciliação integradora, que consiste na eliminação de diferenças aparente, na resolução de inconsistências, na integração dos significados e na ocorrência de superordenação.

Apesar de ocorrer mais por recepção, qualquer tipo de aprendizagem pode ser significativa, desde que relacione o novo conhecimento com os já existentes na estrutura cognitiva do aprendiz, caso contrário a aprendizagem será mecânica, literal e arbitraria. Essa distinção entre a aprendizagem mecânica e significativa a partir da premissa citada e o conceito chave que sustenta o discurso da teoria da assimilação e a variável mais importante nessa teoria é sem dúvida o conhecimento prévio do aprendiz (Ausubel, 2003).

Analogamente as formas de aprendizagem significativa, também pode se distinguir três tipos de aprendizagem significativa por recepção (Havelange, 2009). A representacional; que se assemelha a uma aprendizagem mecânica, pois ela ocorre quando símbolos arbitrários se equiparam a objetos, acontecimentos e conceitos. A Conceitual; entendendo como conceito regularidade em eventos e objetos, ela ocorre quando o sujeito percebe essa regularidade e passa a representá-la por um determinado símbolo, a aprendizagem conceitual é um alto nível da 
aprendizagem representacional e a Proposicional, ela se vale dos dois primeiros tipos de aprendizagem por recepção e ocorre quando a novas ideias adquirem significado através de proposições.

Outro ponto importante dessa teoria são as condições necessárias para que a aprendizagem seja significativa. Segundo Ausubel, 2003, são três essas condições: 0 material apresentado deve ser potencialmente significativo e nunca significativo, pois só possui significado lógico para quem aprende; $\mathbf{O}$ aprendiz deve possuir ideias âncora relevante que permita criar relações com o novo material e $\mathbf{A}$ vontade para fazer essas relações.

A vantagem da aprendizagem significativa sobre a aprendizagem mecânica segundo Moreira, 2013, primeiramente estar no fato de produzirem significado idiossincrático do conteúdo exposto para o aprendiz, isso melhora a capacidade de transferir esse conhecimento a situações novas. Essa capacidade de resolver problemas em um novo contexto pode ser usada como forma de avaliar a aprendizagem significativa. Outra vantagem dessa aprendizagem, estar na maior retenção do conhecimento e na possibilidade de armazenagem, o que quase não ocorre na aprendizagem mecânica. Na figura 1 pode ser observado um mapa conceitual que resume as caracteristicas da aprendizagem significativa aqui mecionada.

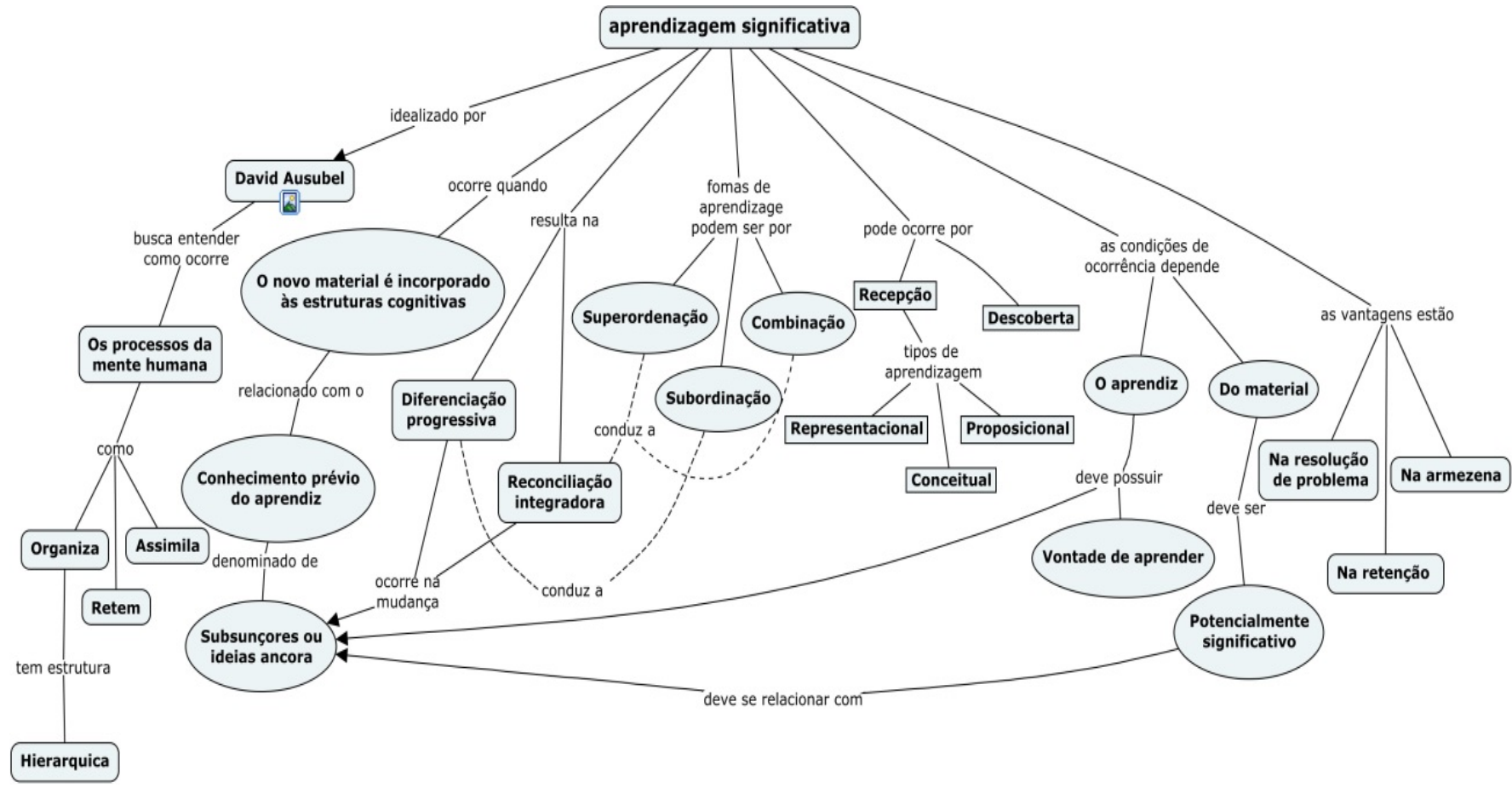

Figura 1- Mapa conceitual sobre aprendizagem significativa, tendo a seguinte questão focal; como ocorre a aprendizagem significativa?

\section{MAPA CONCEITUAL}

Os mapas conceituais foram desenvolvidos por Joseph Novak em 1972 através do programa de pesquisa realizado na Universidade de Cornel e tinha como objetivo acompanhar e entender as mudanças na maneira como as crianças aprendiam ciências (Novak e Cañas, 2010). Nesse programa de pesquisa surgiram dificuldades com utilização de entrevistas transcritas para identificar como ocorriam mudanças específicas na compreensão de conceitos científicos, a partir 
desse problema surgiu a ideia de representar o conhecimento infantil através de mapas conceituais.

Eles são diagramas que servem para representar o conhecimento que o indivíduo tem sobre determinado tema, externalizando a relação e a organização dos conceitos e das proposições existentes na sua estrutura cognitiva (Moreira 2013). Além disso, no processo da elaboração dos mapas conceituais podem ser esclarecidas as relações entre conceitos antes obscuras, como também podem ser percebidas novas relações, desse modo os mapas conceituais se apresentam também como ferramentas criativas, que sevem para desenvolver novos conhecimentos (Novak e Gowin, 1996).

Para Gava, Davidson e Cury, 2005, os elementos dos mapas conceituais são basicamente três: 1 - Os nós, que podem ser representados por figuras geométricas, onde geralmente estão localizados conceitos, no entanto pode ser encontrado nos nós textos, vídeos, imagens, áudios, outros mapas conceituais e páginas da web. Programas de computador como o Cmap Tools permite o uso desse recurso multimidiático. 2 - As frases de ligação, que através de linhas e setas unem os conceitos, evidenciando uma relação entre eles. A cada relação entre dois conceitos ocorrida através de uma frase ligação é obtida uma proposição. Desse modo os mapas conceituais se utilizam dos três tipos de aprendizagem significativa por recepção. 3 - A questão focal, que é geralmente uma pergunta que deve ser respondida pelo mapa conceitual, ela serve para direcionar a construção e a leitura dessa ferramenta gráfica (Novak e Cañas, 2010).

que relação trata a segunda lei de Newton?

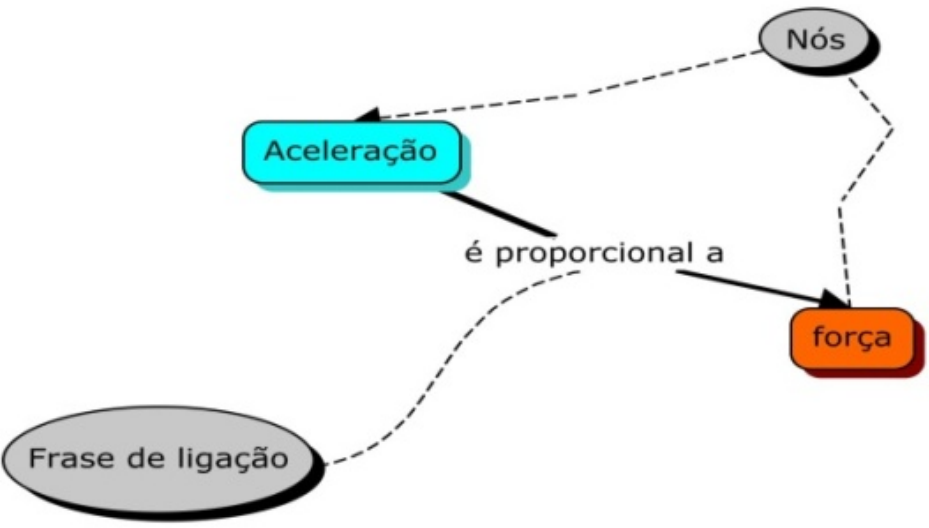

Figura 2- Exemplo simples dos elementos de um mapa conceitual.

Outro ponto importante são as ligações feitas entre conceitos de áreas distante do mapa, denominados de ligações cruzadas, elas demonstram um domínio do conteúdo por parte de quem o elaborou, como também podem representar saltos criativos.

Os mapas conceituais foram desenvolvidos com base na teoria da assimilação, por esse motivo sua estrutura deve ser hierárquica. Isso pode ser visto, por exemplo, nos mapas no qual os conceitos mais inclusivos ficam dispostos no topo da hierarquia (parte superior do mapa), enquanto os conceitos mais específicos ficam localizados na base (parte inferior do mapa). Contudo, esta configuração de organização dos conceitos não é obrigatória, apesar de facilitar a 
construção e a leitura dos mapas conceituais. A única exigência deles, é que devem deixar bem claro na sua estrutura quais os conceitos contextualmente são mais importantes e quais são mais específicos. Para isso, podem-se usar setas, para direcionar a leitura, como também formas geométricas diferentes e variar o tamanho da fonte das letras, tentando fazer uma distinção entre conceitos com relação a sua posição hierárquica.

Além de possuir uma estrutura hierárquica, é possível encontrar nos mapas conceituais marcas da diferenciação progressiva e da reconciliação integradora, como também é possível visualizar as relações de subordinação entre os conceitos (Nakamoto e Takahashi, 2005). Quando ocorre a aprendizagem significativa a estrutura cognitiva muda através dos processos citados, com isso é necessário reelaborar constantemente os mapas conceituais, até mesmos na primeira elaboração de um mapa é preciso variar a posição dos nós e das frases de ligação para que eles assumam a forma desejada. Programas de computador são ferramentas ótimas para essa finalidade, pois permitem a mobilidade que é necessária para se trabalhar com essa ferramenta.

Todos os mapas conceituais contidos nesse trabalho, foram elaborados no Cmap tools, esse programa foi desenvolvido no Instituto de Cognição Homem-Máquina (IHMC) da Universityof West Florida e está disponível para download gratuito na Internet no site http://cmap.ihmc.us. Essa ferramenta digital, além de facilitara construção dos mapas e permitir anexar vários tipos de mídias, associada com a internet, ela possibilita a construção coletiva online dos mapas e também a publicação deles em diversos formatos de arquivo, com fácil acesso para qualquer internauta (Novak e Cañas, 2010).

\subsection{O USO DE MAPAS CONCEITUAIS DO ENSINO DE FÍSICA}

O uso dos mapas conceituais no ensino de física se mostra promissor. Primeiramente pela forma como se organiza o pensamento cientifico, em postulados, axiomas e teoremas (Proença, 2010). Essa configuração hierárquica do pensamento científico pode ser facilmente evidenciada com o uso dos mapas, eles também podem representar relações entre grandezas e conceitos físicos, ponto crucial no estudo dos fenômenos físicos, vale ressaltar que conceitos iguais podem assumir funções hierárquicas diferentes dependendo do temo abordado. Em segundo lugar, por eles serem uma representação da estrutura cognitiva do indivíduo e por serem fundamentados em uma teoria solida da aprendizagem.

Outro ponto que contribui para sua utilização é o fato de que existe uma vasta bibliografia e exemplos a respeito dessa ferramenta, isso facilita o estudo e o uso deles por parte do professor (Araujo, 2015). Na figura 3 e 4 podem ser observados propostas, exemplos, de dois mapas conceituas sobre áreas diferentes da Física, obtido em um site sobre demonstrações experimentas, eles exemplificam os argumentos aqui citado. 


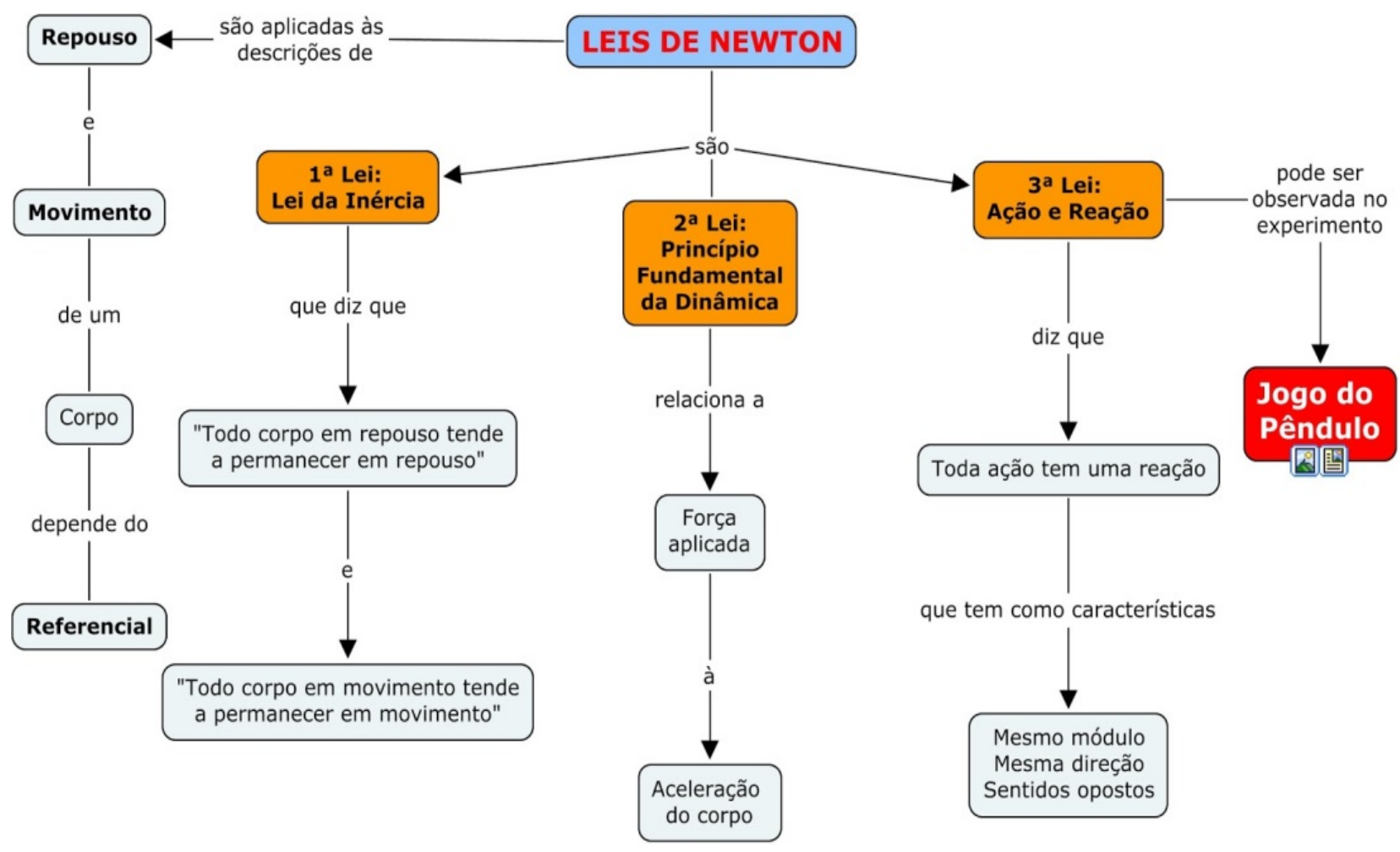

Figura 3-Mapa conceitual sobre as leis de Newton

(Fonte; http://experimentandofisica.blogspot.com.br/2012/12/mapas-conceituais_10.html).

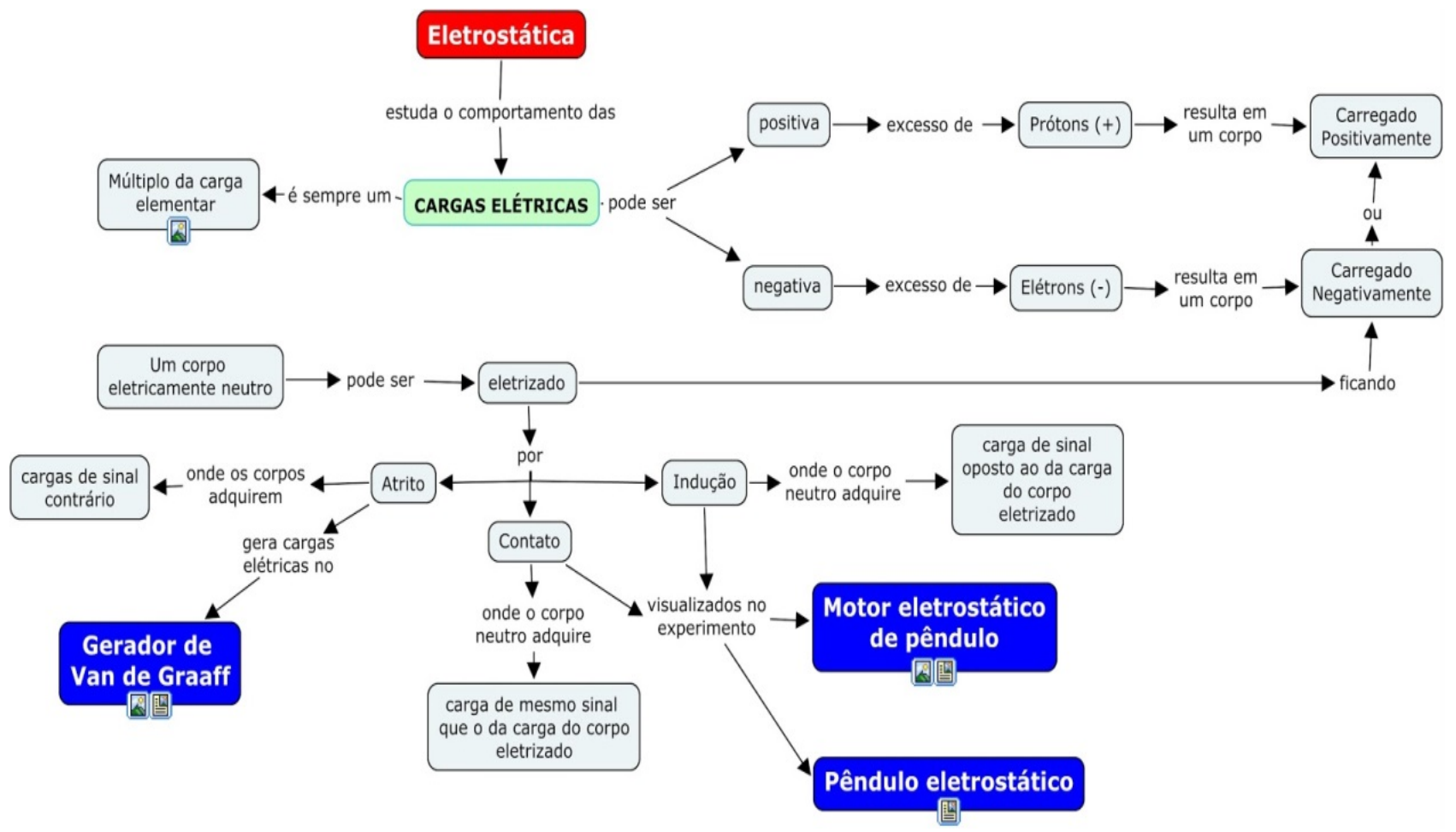

Figura 4-Mapa conceitual sobre eletrostática

Fonte; http://experimentandofisica.blogspot.com.br/2012/12/mapas-conceituais_10.html 
Além de serem usados para representar, organizar e criar conhecimento, os mapas conceituais possuem várias aplicações no ensino, tanto para professores como para alunos. Para os alunos os mapas conceituais podem ser usados, por exemplo, para fazer anotações, trocar ideias sobre um tema, resolver problemas, planejar o estudo e/ou a redação de grandes relatórios, fazer síntese de um texto, preparar-se para avaliações, apresentar trabalho e identificar integração entre tópicos. Para os professores, eles podem ser uma ferramenta poderosa para auxiliar em tarefas rotineiras do ensino, como por exemplo, ensinar um novo tópico, reforçar a explicação, analisar currículos, organizar o conteúdo e avaliar a aprendizagem. Os mapas conceituais assumem um papel importante quando usados como ferramentas de avaliação.

\subsection{MAPAS CONCEITUAIS COMO FERRAMENTAS DE AVALIAÇÃO}

Nesse tópico iremos propor uma estratégia para o uso dos mapas conceituais como ferramenta para avaliação qualitativa, um recurso para o professor visualizar e acompanhar o desenvolvimento do aluno na aprendizagem de determinado conteúdo, para que desta forma suas ações possam interagir de forma significativa com os conhecimentos do aprendiz.

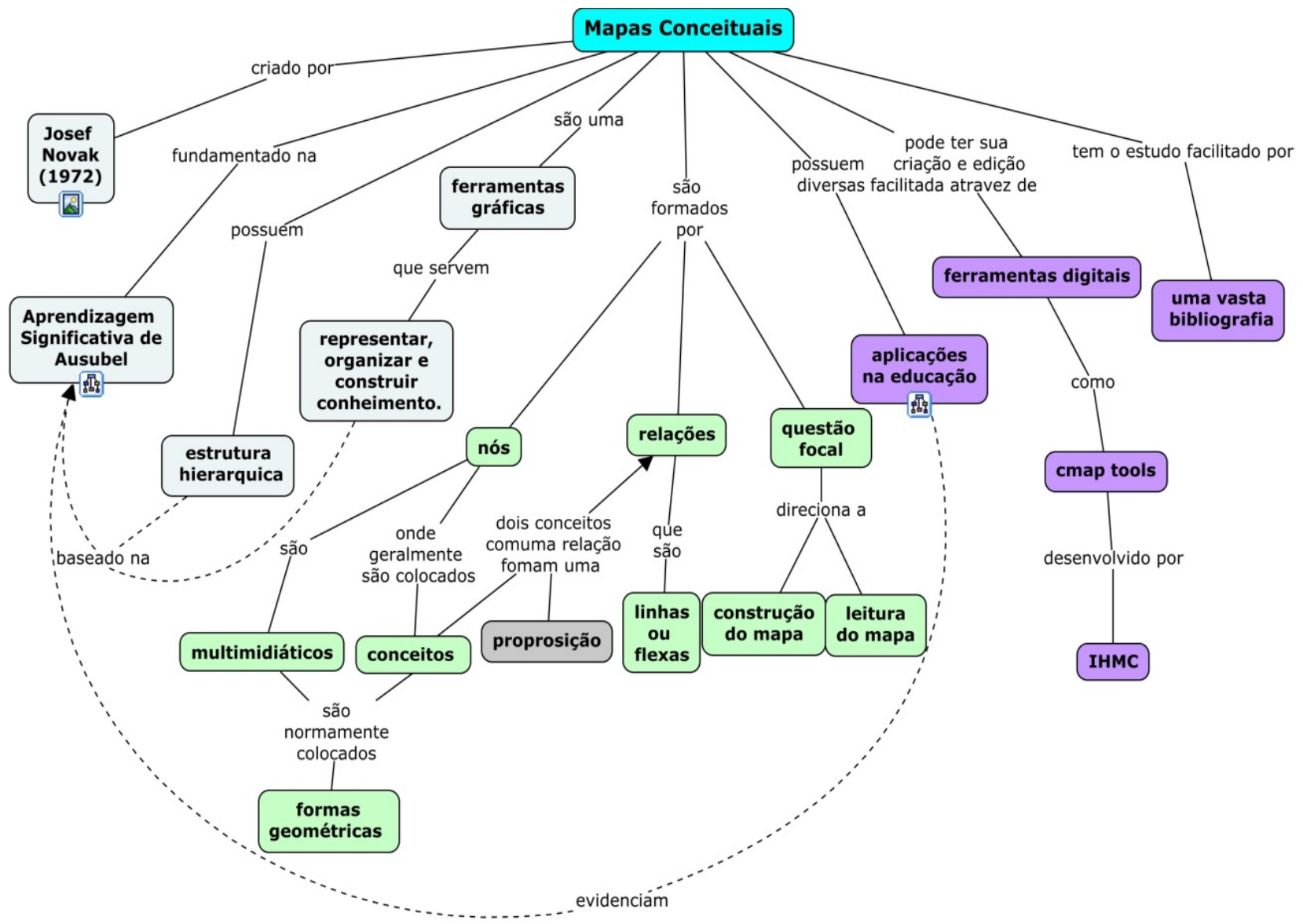

Figura 5 - Síntese do que foi trato sobre os Mapas conceituais.

\section{APLICAÇÃO DOS MAPAS COMO FERRAMENTA DE AVALIAÇÃO QUALITATIVA.}

O processo de avaliar a aprendizagem não é algo que se dá em um vazio teórico, ele é fundamentado em um modelo de mundo, de ciência e de educação, que se traduzem em práticas 
pedagógicas (Demo, 2001). Com base em suas concepções pedagógicas, os professores atribuem sentidos e significados à avaliação escolar. Nesse sentido, a concepção da avaliação qualitativa, abordada neste artigo, não se opõe ou substitui de alguma forma a avaliação quantitativa. No entanto, ela pretende ultrapassar os paradigmas historicamente consolidados pela avaliação quantitativa.

Para poder esclarecer o significado da avaliação na educação e na sociedade, serão abordadas de forma breve algumas concepções pedagógicas de avaliação com tendências quantitativas e ao final a concepção de avaliação qualitativa (Chueiri, 2008).

Examinar para avaliar; é uma perspectiva de avaliar sob forma de exames e provas, foram usadas a partir de três mil anos antes de cristo pelos chineses e a partir do século XVI em escolas católicas da ordem jesuítica e em escolas protestastes. Essa concepção de avaliar atingiu o seu apogeu com a ascensão e consolidação da burguesia e ainda hoje, geralmente de forma bem sistematizada, se utiliza esse tipo de avaliação na prática escolar.

Avaliar para medir; essa concepção se iniciou no século XX, com uma abordagem estritamente quantitativa, desenvolveu testes padronizados para medir as habilidades e as aptidões dos alunos. A psicologia comportamentalista fundamenta tanto esta concepção de avaliar, como também a pedagogia tecnicista, que utilizava a educação como ferramenta para mudar o comportamento do indivíduo.

Avaliar para regular ou classificar; é uma das concepções mais tradicionais da educação. A primeira assume um caráter de certificação, isto é, o diploma garante que individuo recebeu uma formação e não necessita de novos exames para atestar isso. A segunda trata de um caráter mais comparativo no qual os alunos são classificados segundo uma norma de excelência. Essa concepção de avaliar tem uma grande importância na para sociedade, pois ela serve como garantia que o indivíduo sabe habilidades necessárias para obter um determinado emprego e para continuação dos estudos.

Avaliar para qualificar; surge como uma resposta a deficiência da avaliação quantitativa em obter informações relevantes da compreensão dos alunos sobre determinado conteúdo e das concepções tecnicistas para o ensino. A avaliação qualitativa estar centrada na compreensão do processo de aprendizagem do indivíduo, por esse motivo possui uma concepção formativa. Em quanto, a avaliação quantitativa que tem como objetivo atribuir valor numérico, geralmente com situações previamente estabelecidas pelo professor, a aprendizagem, com se ale fosse um produto final do ensino, por esse motivo possui uma concepção somática classificatória.

Avaliação qualitativa necessita de ferramentas que externalize o conhecimento do aluno, geralmente a ferramenta utilizada são textos escritos que possui uma estrutura de pensamento linear. No entanto existem diversas linguagens para representa o conhecimento, sendo uma delas o uso dos mapas conceituais. Em ralação aos textos, a elaboração e a leitura dos mapas conceituais exigem um menor esforço cognitivo, além disso, essa ferramenta foi criada para representar, segundo a teoria da assimilação, a estrutura cognitiva do aprendiz. Desta forma os mapas conceituais se revelam com uma ótima ferramenta para avaliar o processo de desenvolvimento do aluno.

Nesse sentido, propomos uma estratégia metodológica para o uso dos mapas conceituais como ferramenta de avaliação qualitativa, mas primeiro será abordado duas técnicas (Novak e 
Cañas, 2010) que facilitam a construção dos mapas para alunos que não possui essa prática; o estacionamento e o esqueleto.

A técnica do estacionamento consiste em dispor aos alunos uma lista de nós (conceitos) para serem inseridos em um mapa conceitual. Essa lista de nós contém conceitos que o professor deseja que os alunos coloquem em um mapa conceitual para resolver uma questão focal, no entanto eles podem incluir outros conceitos que não existem na lista, que em suas concepções são importantes para resolver o problema.

Apesar de parece ter facilitado muito a tarefa do aluno na construção dos mapas, pesquisas demonstram que o aspecto mais desafiado na elaboração do mapa e a criação de proposições, ou seja, determina frases de ligação que demostre de forma clara o relacionamento entre os conceitos. Esta técnica oferece ao professor um meio de analisar quais os problemas que o aluno tem para relacionar alguns conceitos. No entanto ela de certa forma limitar a criatividade do aprendiz. Na figura 6 podemos ver um exemplo dessa técnica tomando como referência o mapa conceitual da figura 4, que pode ter como questão focal: que fundamento cientifico explica o gerador de Van Graff, o motor de eletrostático pêndulo e pêndulo eletrostático?

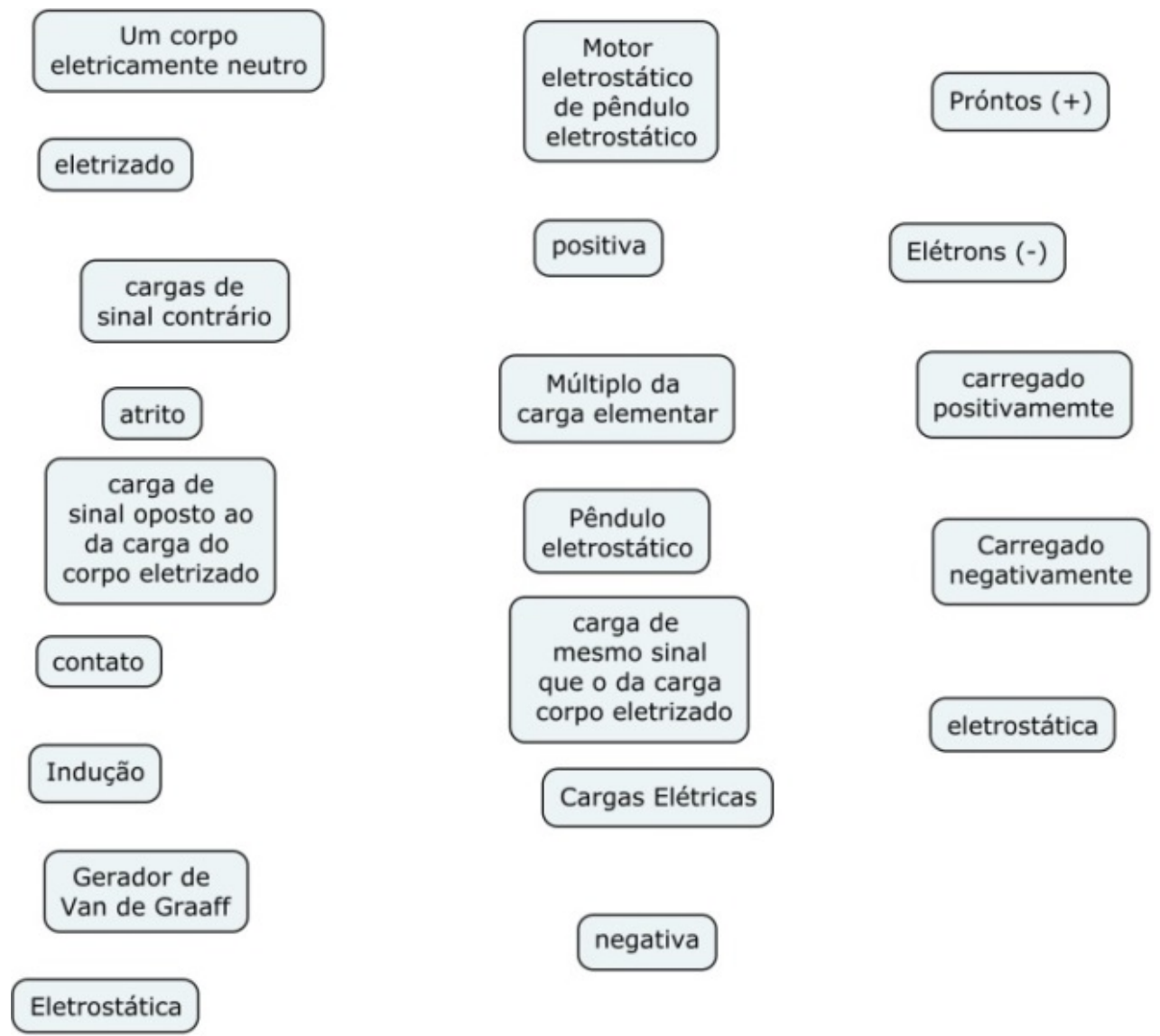

Figura 6 - Exemplo da técnica do estacionamento.

A técnica do esqueleto consiste em construí um mapa base, geralmente com poucos conceitos, que servem como suporte para construção do conhecimento, no qual o aluno o complementa com novos conceitos. O professor deve ter muito cuidado em usa essa técnica, 
pois ele deve selecionar um pequeno grupo de conceitos essenciais para entendimento do tópico escolhido e expressar de forma precisa o relacionamento entre eles.

A técnica do esqueleto e um ótimo suporte para o ensino de Física, pois ele pode evidenciar conceitos chaves mais gerais e inclusivos no mapa, permitindo ao aluno inserir conceitos e proposições mais especificas. Na figura 7 contém um exemplo dessa técnica que possui a mesma questão focal do exemplo da técnica do estacionamento.

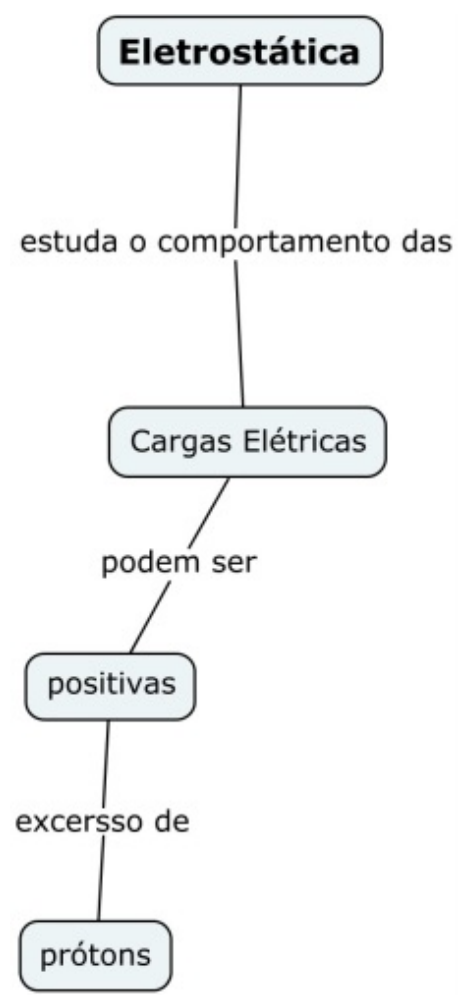

Figura 7 - Exemplo da técnica do esqueleto.

E ainda podem ser utilizadas as duas técnicas no mesmo mapa conceitual. Nessa abordagem o professor dever ter o senso crítico de fazer um esqueleto razoavelmente pequeno colocar dispor uma boa quantidade de conceitos estacionados, para não limitar demais a criatividade do aluno. Esta última técnica pode servi como incentivo inicial para construção dos mapas. A figura 8 exemplifica o uso dessa técnica, e possui a mesma questão focal das duas primeiras técnicas. 

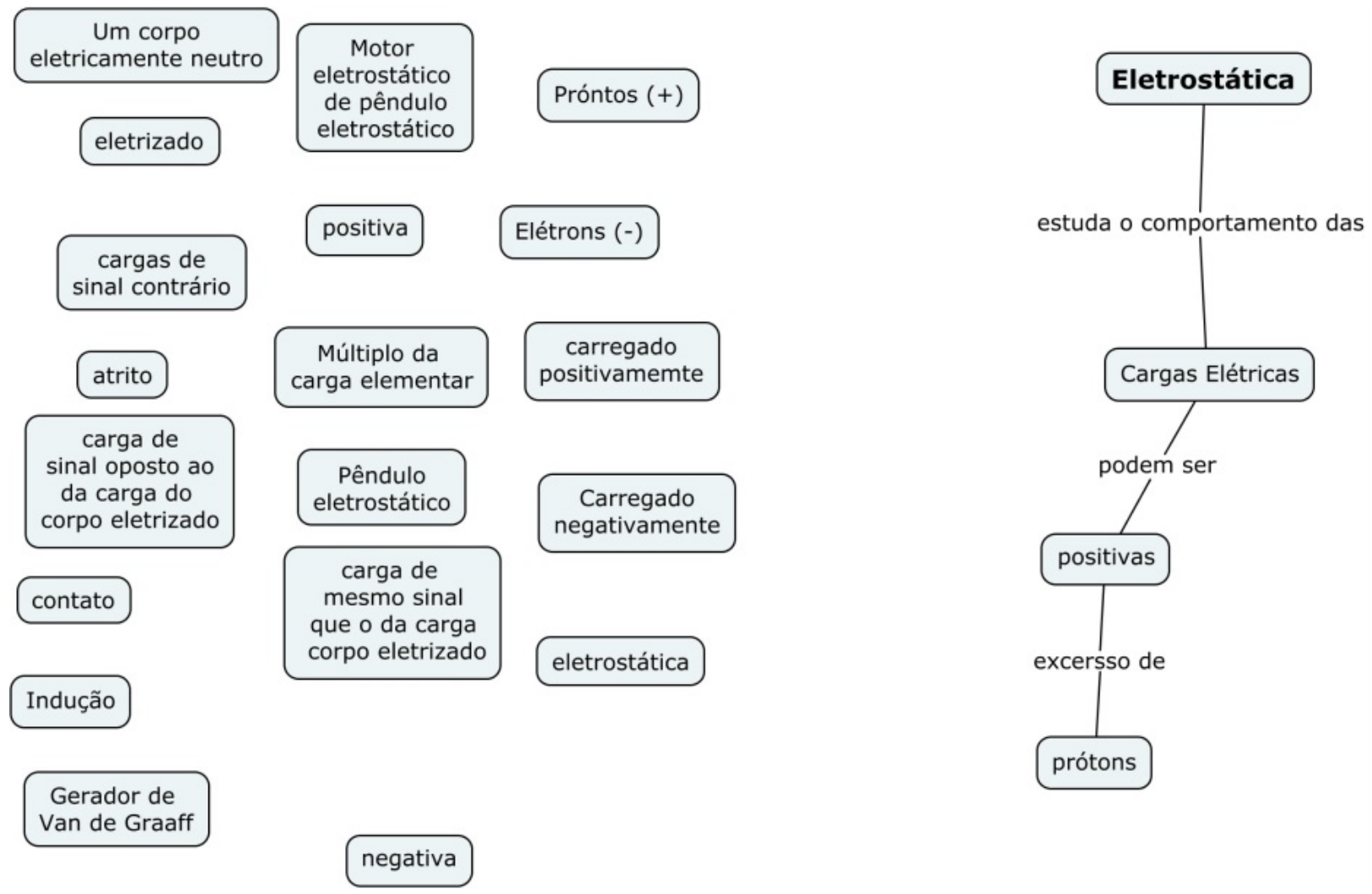

Figura 8 - Exemplo das duas técnicas no mesmo mapa.

Através das ideias aqui abortadas propomos uma lista de procedimentos metodológicos que auxiliem a utilização dos mapas conceituais como ferramenta de avaliação qualitativa.

1- No primeiro momento, o professor deve apresentar com uma síntese do que são os mapas conceituais, para que servem e como se estruturam. Expor de forma bem clara a função da questão focal, a definição de conceito e de frases de ligação.

2- O professor deve criar proposições simples, através de questões focais que abordem o cotidiano do discente. Deve incentivar os estudantes a fazer individualmente um pequeno mapa sobre o tema. Por exemplo, pode ser abordado um tema como: para que serve os carros? Esta etapa serve apenas para iniciar os alunos no processo de construção dos mapas através de exemplos simples, diagnosticando e ajudando aqueles que tem mais dificuldade nesse processo.

3- O professor deve dividir a sala preferencialmente em grupos de três a cinco alunos, para que eles possam negociar e trocar conhecimentos com os integrantes do seu grupo acerca da questão focal colocada, enriquecendo e dinamizando ainda mais o processo de construção dos mapas.

4- Com os grupos formados, o professor pode começar a expor o conteúdo programático da forma que the convém, no entanto ele deve ter cuidado em abordar o conteúdo, que deve partir de conceitos mais gerais e inclusivos para conceitos específicos, como orienta a teoria da assimilação.

5- O professor deve pedir aos grupos que durante a exposição do conteúdo eles selecionem conceitos que Ihes parecem mais importantes no discurso. Nessa etapa o 
professor poderá verificar se os conceitos selecionados são os mais relevantes para o tema em questão.

6- Em seguida, o professor já pode pedir aos alunos para iniciar a construção dos mapas. Com o uso do programa Cmap Tools essa etapa pode ser gravada. Para facilitar a iniciação dos alunos no uso dessa ferramenta, o professor pode usar as técnicas do estacionamento e/ou do esqueleto, sendo a mais fácil para iniciar os alunos no uso dessa ferramenta, a mescla das duas.

7- Após a elaboração dos mapas, os grupos devem fazer um pequeno texto explicando as proposições que foram usadas, pois essa ferramenta não é autoexplicativa.

8- É preferível que seja feita as apresentações dos mapas conceituais por todos os grupos formados em sala, no entanto se o tempo não permitir, o professor deverá selecionar alguns grupos para fazer essa tarefa. Isso obriga a participação de todos os alunos na elaboração dos mapas, já que todos têm a possibilidade de apresentá-lo para a sala, além disso, essas apresentações devem trazer uma discussão acerca das diferenças e semelhanças encontradas nos mapas dos grupos.

Para poder avaliar a aprendizagem significativa é necessário criar situações problemas em um novo contexto, isso pode ser feito com o uso dos mapas, variando a questão focal podemos criar situações problemas diferentes, inclusive com graus de dificuldades diferentes. Também podem ser utilizadas as técnicas citadas na construção do mapa, o que também geram situações problemas diferentes, com graus de dificuldades diferentes. Como já foi mencionada a avaliação qualitativa não pretende substituir a avaliação quantitativa, desse modo os mapas podem ser avaliados quantitativamente de forma rigorosa (Novak e Gowin, 1996), apesar de não ser o objetivo desse artigo.

Contudo, não existem mapas conceituais corretos, apesar de alguns serem mais ricos conceitualmente do que outros. Além disso, eles também podem apresentar erros nas frases de ligação e nas relações entre os conceitos. Com isso não é necessário que os grupos saibam todas as relações e os conceitos, eles têm a opção de deixá-las em branco para ser esclarecidas pelo professor.

Esses procedimentos podem parecer trabalhosos no início na sua implementação, mas conforme eles vão sendo incorporados ao ensino, se tornam estratégia comuns, tanto para o professor como para os alunos. Dessa forma, os mapas podem ser usados ao final de cada tópico do conteúdo programático, servindo ao professor como uma poderosa ferramenta de avaliação continua e para o aluno como uma ferramenta de organização e de criação de conhecimentos. Além disso, eles oferecem ao aprendiz uma ideia de como ocorrem as mudanças na sua estrutura cognitiva a partir da aprendizagem, levantando questionamentos a respeito dos processos responsáveis por sua aprendizagem.

\section{CONSIDERAÇÕES FINAIS}

A discursão de referências teóricos é imprescritível para que as ações pedagógicas do professor não ocorram em um vazio conceitual. No entanto, nas suas práticas em sala de aulas do professor necessitam, além de uma boa fundamentação teórica, de ferramentas e estratégias que conduzam ao objetivo que ele 
espera para o ensino. Desta maneira, os mapas conceituais se apresentaram como uma ferramenta que possui diversos usos na educação, contudo eles ainda são pouco utilizados. O uso de mapas conceituais possibilita, por exemplo, que o estudante enxergue o todo do conteúdo e a parti do eixo principal possa entender as partes. A construção e uso de um mapa conceitual requer do discente um conhecimento âncora, um subsunçor, de onde partirá as principais setas, caso o estudante não disponha de um conhecimento prévio do conceito a ser estudado, isto poderá prejudicar o uso de mapas conceituais e o professor deverá buscar outros meios. Nesse sentido, através nas pesquisas realizadas na produção desse artigo, podemos concluir que ações relativamente simples podem conduzir a uma aprendizagem significativa, sem necessariamente ter que fazer grandes mudanças nos recursos didáticos.

\section{REFERÊNCIAS}

Araújo, M. S. T., \& Formenton, R. (2015). Utilização de mapa conceitual como ferramenta de análise de trabalhos científicos. HOLOS, 1, 171-181. AUSUBEL .P .D.; Aquisição e Retenção de Conceitos: Uma Perspectiva Cognitiva.; Paralelo Editora, LDA. Janeiro de 2003

Barbosa, M. L., Alves, A. S., JESUS, J., \& Burnham, T. (2005). Mapas conceituais na avaliação da aprendizagem significativa. Simpósio Nacional de Ensino de Física, 14.

Chuieire, M. S. F. (2008). Concepções sobre a avaliação escolar. Estudos em Avaliação Educacional, 19(39), 49-64.

Soares, L. H. (2009). Aprendizagem Significativa na Educação Matemática: uma proposta para a aprendizagem de Geometria Básica.

Gava, T. B. S., Menezes, C. D., \& Cury, D. (2003, March). Aplicações de mapas conceituais na educação como ferramenta metacognitiva. In III International Conference on Engineering and Computer Education-ICECE (Vol. 16).

Demo, P. (2014). Teoria e prática da avaliação qualitativa. PerspectivasOnLine 2007-2011, 1(1).

Moreira, M. A. (2002). A teoria dos campos conceituais de Vergnaud, o ensino de ciências e a pesquisa nesta área. Investigações em ensino de ciências. Porto Alegre. Vol. 7, n. 1 (jan./mar. 2002), p. 7-29.

MOREIRA, M. A. (2013). Aprendizagem significativa em mapas conceituais. Textos de apoio ao professor de física, do PPGEnFis/IF-UFRGS, 24(6), 1-49.

Nakamoto, P. T., Takahashi, E. K., Mendes, E. B., Cardoso, A., \& Júnior, E. L. (2005). O uso de mapas conceituais e Realidade Virtual para o Ensino da Física no Ensino Médio. Uberlândia, UFU.

Novak, J. D., \& Cañas, A. J. (2010). A teoria subjacente aos mapas conceituais e como elaborá-los e usá-los. Práxis Educativa, 5(1), 9-29.

Novak, J. D., Gowin, D. B., \& Valadares, C. (1996). Aprender a aprender. 
Präss, A. R. (2012). Teorias de aprendizagem. ScriniaLibris. com.

Rosa, C. A. D. P. (2012). História da Ciência: a ciência e o triunfo do pensamento científico no mundo contemporâneo. In História da ciência: a ciência e o triunfo do pensamento científico no mundo contemporâneo.

Souza, R. R. (2005). Uma experiência de uso de mapas conceituais para avaliação de conhecimentos. Sociedade Brasileira de Computação: biblioteca digital.

Tavares, R. (2007). Construindo mapas conceituais. Ciências \& Cognição, 12, 72-85.

Tavares, R. (2008). Animações interativas e mapas conceituais: uma proposta para facilitar a aprendizagem significativa em ciências. Ciências \& Cognição, 13(2), 99-108.

Santana, F. E., Michels, L. B., \& Teixeira-mateus, M. M. USO DE MAPAS CONCEITUAIS NO PROCESSO AVALIATIVO DA EDUCAÇÃO PROFISSIONAL E TECNOLÓGICA: UM ESTUDO DE CASO EM DESENHO ASSISTIDO POR COMPUTADOR.

Toigo, A. M., \& Moreira, M. A. (2008). Relatos de experiência sobre o uso de mapas conceituais como instrumento de avaliação em três disciplinas do curso de Educação Física. Experiências em Ensino de Ciências, 3(2), 7-20.

Veit, E. A., \& Araujo, I. S. (2005). Modelagem computacional no Ensino de Física. Revista do Centro de Educação da Universidade Federal de Alagoas. CEDU-n. 